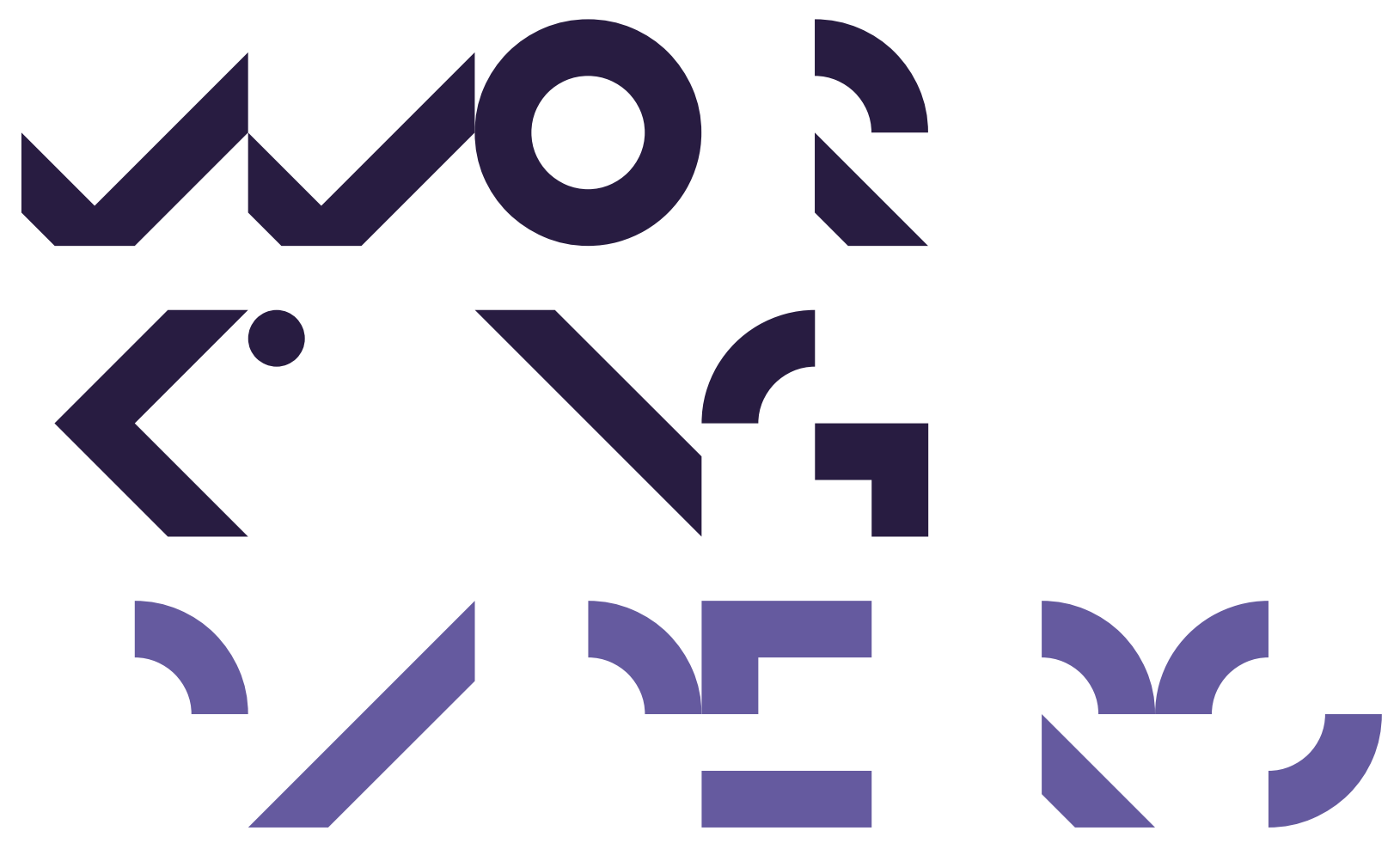

Economics Working Papers

2016-7

Testing for Statistical Discrimination based on Gender Rune V. Lesner

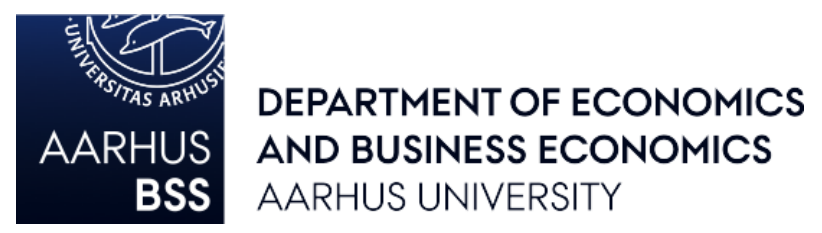




\title{
Testing for Statistical Discrimination based on Gender
}

\author{
Rune V. Lesner
}

9th May 2016

\begin{abstract}
This paper develops a model which incorporates the two most commonly cited strands of the literature on statistical discrimination, namely screening discrimination and stereotyping. The model is used to provide empirical evidence of statistical discrimination based on gender in the labour market. It is shown that the implications of both screening discrimination and stereotyping are consistent with observable wage dynamics. In addition, it is found that the gender wage gap decreases in tenure but increases in job transitions and that the fraction of women in high-ranking positions within a firm does not affect the level of statistical discrimination by gender.
\end{abstract}

JEL classification: J7; J31; D83

Keywords: Statistical discrimination; Wage differentials; Gender gap; Employer learning

Address for correspondence: Department of Economics and Business Economics, Aarhus University, Fuglesangs Allé 4, 8210 Aarhus V, Denmark. Email: rlesner@econ.au.dk. I express my thanks for useful comments on this paper and earlier drafts from Jesper Bagger, Rune Vejlin, and participants in seminars at Nordic Workshop on Register Data and Economic Modeling 2015, 10th Nordic Summer Institute in Labor Economics, and Danish Econometric Society's Annual Meeting 2015. The usual disclaimer applies. 


\section{Introduction}

Gender wage gaps are large and persistent. The sources of these wage differences are important from both a positive and a normative point of view, and they are yet to be settled. Statistical discrimination, as an implication of gender biased responses to incomplete information by employers, is a potential candidate. However, the evidence is scarce.

This paper focuses on the two most commonly cited strands of the literature on statistical discrimination, namely screening discrimination and stereotyping. Stereotyping is based on gender biased beliefs at the mean and screening discrimination is based on gender differences in the noise of the signal. Screening discrimination based on gender occurs when an employer has greater difficulty assessing the productive ability of female workers than male workers and takes this into account when setting wages and thereby discriminate based on gender (Phelps (1972)). An employer is said to be stereotyping if the employer has biased initial beliefs based on gender and uses these beliefs when setting wages (Arrow (1973)) ${ }^{1}$.

This paper develops a model which is able to incorporate both screening discrimination and stereotyping. The model is used to provide empirical evidence on statistical discrimination based on gender. The literature has hitherto not adequately considered these issues due to lack of appropriate data and lack of measured variation in worker abilities. Both of these issues are addressed by using comprehensive Danish administrative data as well as an innovative proxy variable, namely birth weight.

This paper finds evidence of employers using both screening discrimination and stereotyping based on gender when setting wages. In addition, it is found that the fraction of women in high-ranking positions in a firm does not affect the level of statistical discrimination based

\footnotetext{
${ }^{1}$ See Fang and Moro (2011) for a survey on statistical discrimination and Lang and Lehmann (2011) for a discussion of screening discrimination and stereotyping.
} 
on gender. It is also shown that the gender wage gap decreases in tenure but increases in job transitions, which is attributed to a potential gender biased transition cost.

Both screening discrimination and stereotyping are different from the classic preference based discrimination promoted by Becker (1957) in that they are both based on incomplete information which as such can be updated. This difference in the dynamic implications is central in disentangling the statistical discrimination from the classic discrimination.

In order to disentangle these three different types of discrimination, I set up a signalling model with the purpose of obtaining testable implications of both screening discrimination and stereotyping. Integrating screening discrimination and stereotyping into one model and allowing these to interact while still being able to obtain testable implication of each of them is a clear contribution of this paper.

The modelling framework is based on the employer learning literature (Faber and Gibbons (1996), Altonji and Pierret (2001), Schönberg (2007), and Pinkston (2009)), however with a distinct focus on the implications of gender differences. In this line of literature Pinkston (2003) has a framework with a gender focus. He however does not look into stereotyping. This paper extends this line of literature by incorporating stereotyping into an employer learning model and by using the model to obtain clear implications of both screening discrimination and stereotyping based on gender, which are tested on Danish full population data.

The main testable implications from the model can to spit in two. The first implication is that if employers use stereotyping based on gender when setting wages then the wages of women should increase more in tenure than the wages of men. The second implication is that if employers use screening discrimination when setting wages then female wage changes in tenure should be more strongly correlated with worker ability than male wage changes. Both of these implications are confirmed in the data. From this it follows that the data is consistent with 
employers using both screening discrimination and stereotyping based on gender when setting wages.

The implications of the two types of statistical discrimination are tested using Danish administrative matched employer-employee full population data. The validity of the empirical results in the employer learning literature hinges on the possibility of comparing otherwise similar individuals. Using this very rich data source makes it possible to take out much more of the irrelevant variation in the wages than what has previously been done in the employer learning literature.

The major challenge when testing for screening discrimination is that a measure of the productive ability of the worker not completely observable to the employer when setting the wage has to be available. The most commonly used type of measure is military test scores. Using such a measure will however make it hard to assess gender differences. This problem might be the reason as to why, despite a large theoretical literature on the topic of screening discrimination based on gender, it is rarely tested empirically. Pinkston (2003) tests for screening discrimination based on gender using a current and a retrospective performance evaluation of the worker assessed by the employer. The paper finds some indications of statistical discrimination based on gender, but it is limited by a very small sample size. Contrary to this literature, the literature on screening discrimination of male workers based on race is more generally studied. Pinkston (2006) finds evidence of screening discrimination of black male workers. This result is less clear in Altonji and Pierret (2001) and Mansour (2012).

I contribute to this line of research by being able to provide evidence of screening discrimination based on gender. I do this by using a novel measure of worker productive ability available for all workers (birth weight) and by taking advantage of the intergenerational links in the Danish register data (using schooling and labour market income of the father). Birth weight as a 
measure of the productive ability of a worker proves very useful and can be recommended for other studies seeking such a measure.

The paper proceeds as follows. In the next section I describe the model and derive the testable implication of statistical discrimination. The data, sample selection and the measure of worker productive ability are described in Section 3. Section 4 goes through the empirical method. Section 5 shows and comments on the results and provides some robustness tests. Section 6 concludes.

\section{Model}

This section uses a simple framework to discuss the predictions of statistical discrimination by gender in the form of screening discrimination and stereotyping. The modelling framework is based on the employer learning literature (Faber and Gibbons (1996), Altonji and Pierret (2001)), but it is modified in order to incorporate both screening discrimination and stereotyping and simplified to specifically focus on gender differences.

\subsection{Basic setup}

In order to keep the model tractable and the channels of the implications clear, the environment is simplified by assuming that a worker $i$ draws $\log$ productive ability $q^{i}$ from the common underlying distribution $N\left(\bar{\mu}, \sigma^{2}\right)$. This assumption effectively assumes any gender ability differences away. In practice the modelling setup should be thought of as describing an environment where all actual gender differences are taken into account ex-ante.

The model is essentially a signalling model describing the dynamics arising from incomplete information. Specifically, employers do not observe the actual value of the log productive ability 
of the worker $q^{i}$ but instead a noisy signal $s^{i}$ and the gender of the worker $(j)$. In each period $t$ the employer receives a signal of the ability of the worker:

$$
s_{t j}^{i}=q^{i}+\varepsilon_{t j}^{i}
$$

where $\varepsilon_{t j} \sim N\left(\bar{\varepsilon}_{t j}, \sigma_{\varepsilon_{t j}}^{2}\right)$ and $j=M($ ale $), F$ (emale $)$.

The employer relies on all the previous signals to form expectations of the productive ability of the worker. The assessment by the employer of the productive ability of the worker will converge towards the true value if the weight put on the initial potentially biased and noisy signal decreases over time and the initial wrongful belief and noise of the signal is updated.

In particular, if noise reduction is present, then it must be the case that the variance of the initial signal observed by the employer is larger than all later signals $\left(\sigma_{\varepsilon_{0 j}}^{2}>\sigma_{\varepsilon_{t j}}^{2}\right.$ for all $\left.t>0\right)$. In the following I will make the tractability assumption that all signals observed after the initial signal observed at the time of hiring will have the common variance $\left(\sigma_{\varepsilon_{t j}}^{2}=\sigma_{\varepsilon_{j}}^{2} \text { for all } t>0\right)^{2}$.

If the employer is able to update his/her beliefs when receiving additional signals, then it must be the case that $\bar{\varepsilon}_{0 j}<\bar{\varepsilon}_{t j}$. In the following I will make the tractability assumption that $\bar{\varepsilon}_{t j}=\bar{\varepsilon}$ for all $t>0^{3}$. This assumption implies that the initial signal at the time of hiring is subject to a larger degree of biased beliefs than all later signals.

Given these assumptions it follows that the signal $\left(s_{t j}^{i}\right)$ observed by the employer at time $t$ will be a draw from the following distribution:

$$
s_{t j}^{i} \sim N\left(\begin{array}{cc}
\bar{\mu}+\bar{\varepsilon}_{0 j}, \sigma_{0 t}^{2} & \text { if } t=0 \\
\bar{\mu}+\bar{\varepsilon}, \sigma_{t}^{2} & \text { otherwise }
\end{array}\right),
$$

where $\sigma_{0 j}^{2}=\sigma^{2}+\sigma_{\varepsilon_{0 j}}^{2}$ and $\sigma_{t}^{2}=\sigma^{2}+\sigma_{\varepsilon_{j}}^{2}$.

\footnotetext{
${ }^{2}$ For the implications below to be valid, the necessary condition is that $\sigma_{\varepsilon_{t j}}^{2} \geq \sigma_{\varepsilon_{t+1 j}}^{2}$ for all $t>0$.

${ }^{3}$ For the implications in the following to be valid, the necessary condition is that $\bar{\varepsilon}_{\varepsilon_{t j}} \leq \bar{\varepsilon}_{\varepsilon_{t+1 j}}$ for all $t>0$.
} 
The employer will base his/her assessment of the worker on the set of all previous signals.

Since all signals are normally distributed and the error terms are assumed to be independent, the updated signal at time $t\left(S_{j}^{i}(t)\right)$ based on all previous signals will be of the following form:

$$
S_{j}^{i}(t)=q^{i}+\alpha_{0 j} \varepsilon_{0 j}^{i}+\alpha_{t j} \sum_{\tau=1}^{t} \varepsilon_{\tau j}^{i},
$$

where $\alpha_{0 j}=\frac{\sigma_{t}^{2}}{t \sigma_{0 j}^{2}+\sigma_{t}^{2}}, \alpha_{t j}=\frac{\sigma_{0 j}^{2}}{t \sigma_{0 j}^{2}+\sigma_{t}^{2}}$.

The assessment is the sum of the actual productive ability of the worker and a weighted sum of the noise in all previous periods where the weights will be based on the difference in the variance of the signals. The updated signal of the worker at time $t$ will then be a draw from the following distribution:

$$
S_{j}^{i}(t) \sim N\left(\bar{\mu}_{S_{j}(t)}, \sigma_{S_{j}(t)}^{2}\right)
$$

where $\bar{\mu}_{S_{j}(t)}=\bar{\mu}+\alpha_{0 j} \bar{\varepsilon}_{0 j}+\alpha_{t j} t \bar{\varepsilon}$ and $\sigma_{S_{j}(t)}^{2}=\sigma^{2}+\alpha_{1 j}$ with $\alpha_{1 j}=\frac{\sigma_{t}^{2} \sigma_{0}^{2}}{t \sigma_{0}^{2}+\sigma_{t}^{2}} 4$.

Based on the updated signal at time $t$ the employer will form an expectation of the log productive ability of the worker. Assuming that the updated signal and the ability of the worker are independent, the expectation can be described as:

$$
\begin{aligned}
E\left[q^{i} \mid S_{j}^{i}(t)\right] & =\bar{\mu}_{S_{j}(t)}+\frac{\sigma^{2}}{\sigma^{2}+\sigma_{S_{j}(t)}^{2}}\left(S_{j}^{i}(t)-\bar{\mu}_{S_{j}(t)}\right) \\
& =\frac{\sigma_{S_{j}(t)}^{2}}{\sigma^{2}+\sigma_{S_{j}(t)}^{2}} \bar{\mu}_{S_{j}(t)}+\frac{\sigma^{2}}{\sigma^{2}+\sigma_{S_{j}(t)}^{2}} S_{j}^{i}(t) .
\end{aligned}
$$

This expression shows that the expected productive ability of the worker at time $t$ will be a convex combination of the updated signal at time $t$ and the expected mean productive ability

\footnotetext{
${ }^{4}$ See A.1 Appendix for details on the calculations in this section.
} 
in the subpopulation. Assuming that the wage of a worker is given by the expected productive ability, the log wage $w_{t j}^{i}$ of worker $i$ at time $t$ will be given by $w_{t j}^{i}=E\left[q^{i} \mid S_{j}^{i}(t)\right]^{5}$.

If the signal is highly noisy, a higher weight will be put on the expected subpopulation mean, and the expectation will also be affected by any potential biased beliefs of the productive ability of the worker. Over time the variance of the updated signal will decrease $\left(\frac{\partial \sigma_{S_{j}(t)}^{2}}{\partial t}<0\right)$ which will give rise to a higher correlation between the actual productive ability of the worker and the wage. This observation can be interpreted as stating that if the correlation between the actual productive ability of the worker and the wage is increasing over time then this is an indication of employer learning in the form of noise reduction.

A similar observation can be thought of based on the updated beliefs of the employer. The average wage of workers from subgroup $j$ at time $t$ will be given by: $E\left[w_{t j}\right]=\bar{\mu}_{S_{j}(t)}$. From this it follows that if initial beliefs are biased then the subgroup average wage will be increasing over time $\left(\frac{\partial E\left[w_{t j}\right]}{\partial t}>0\right)$ due to a lower weight on the initial biased signal.

The next section looks into the implications for the wage of gender differences in the initial noise and beliefs.

\subsection{Introducing gender differences}

In this modelling setup gender differences can arise through either differences in the noise of the initial signal at the time of hiring $\left(\sigma_{\varepsilon_{0 j}}^{2}\right)$ or through differences in the initial beliefs by the employer about the productive ability of the worker $\left(\bar{\varepsilon}_{0 j}\right)$. Implications of each of these on the wages of workers can be thought of as statistical discrimination based on gender. In this section these implications will be described.

Gender differences in the noise of the initial signal are often denoted as screening discrimin-

\footnotetext{
${ }^{5}$ Risk neutrality is imposed in order to abstract from long-term wage contracts.
} 
ation in the literature (Phelps (1972)). In particular, if employers have greater difficulty assessing the productive ability of female workers than male worker $\left(\sigma_{\varepsilon_{0 M}}^{2}<\sigma_{\varepsilon_{0 F}}^{2}\right)$, then employers will use this information when setting wages and thereby screening discriminate based on gender. In equation (5) it can be seen that if the variance of the updated signal is high then the wage will rely less on the signal and more on the expected subpopulation mean. It can also be shown that the variance of the updated signal is increasing in the variance of the initial signal $\left(\frac{\partial \sigma_{S_{j}(t)}^{2}}{\partial \sigma_{\varepsilon_{0 j}}^{2}}>0\right){ }^{6}$. This implies that if employers screening discriminate based on gender then the wages of women should be less strongly correlated with their actual productive ability than the wages of men.

In the previous section it was described that the correlation between the productive ability and the wage of the worker will increase over time if employers are able to learn. It can further be shown that this learning process will be faster for women than for men if employers are using screening discrimination $\left(\frac{\partial^{2} \sigma_{s t}^{2}}{\partial \sigma_{\varepsilon_{0 j}}^{2} \partial t}<0\right)$.

If employers have biased initial beliefs based on gender $\left(\bar{\varepsilon}_{0 M}>\bar{\varepsilon}_{0 F}\right)$, then this will have implications for the wage. In this paper the statistical discrimination arising from this is labelled employer stereotyping (Arrow (1973)). If employers use stereotyping based on gender when setting wages, then the average wage of women will be lower than the average wage of men $\left(\frac{\partial E\left[w_{t j}\right]}{\partial \bar{\varepsilon}_{j 0}}>0\right)$. But it will also be the case that as time progresses and the weight of the initial signal decreases the increase in wages of women will be larger than the increase of wages of $\operatorname{men}\left(\frac{\partial^{2} E\left[w_{t j}\right]}{\partial t \partial \bar{\varepsilon}_{j 0}}<0\right)$.

Notice that screening discrimination will only affect the gender gap in average wages if stereotyping is present, in which case the screening discrimination will dampen the effect of the stereotyping because less weight will be put on the initial biased signal

\footnotetext{
${ }^{6}$ See A.2 Appendix for details on the calculations in this section.
} 
$\left(\frac{\partial^{2} E\left[w_{t j}\right]}{\partial \sigma_{\varepsilon_{0 j}}^{2} \partial \bar{\varepsilon}_{j 0}}<0\right.$ and $\left.\frac{\partial^{3} E\left[w_{t j}\right]}{\partial \sigma_{\varepsilon_{0 j}}^{2} \partial \bar{\varepsilon}_{j 0} \partial t}>0\right)$.

Figure 1 illustrates this important aspect of having both types of statistical discrimination in one model. The graph on the left in Figure 1 shows the gender wage gap as a function of tenure. The graph on the right shows the gender wage gap as a function of the productive ability of the worker. The figure illustrates the main intuition of the three scenarios; stereotyping, screening discrimination, and the case where both types of discrimination are present.
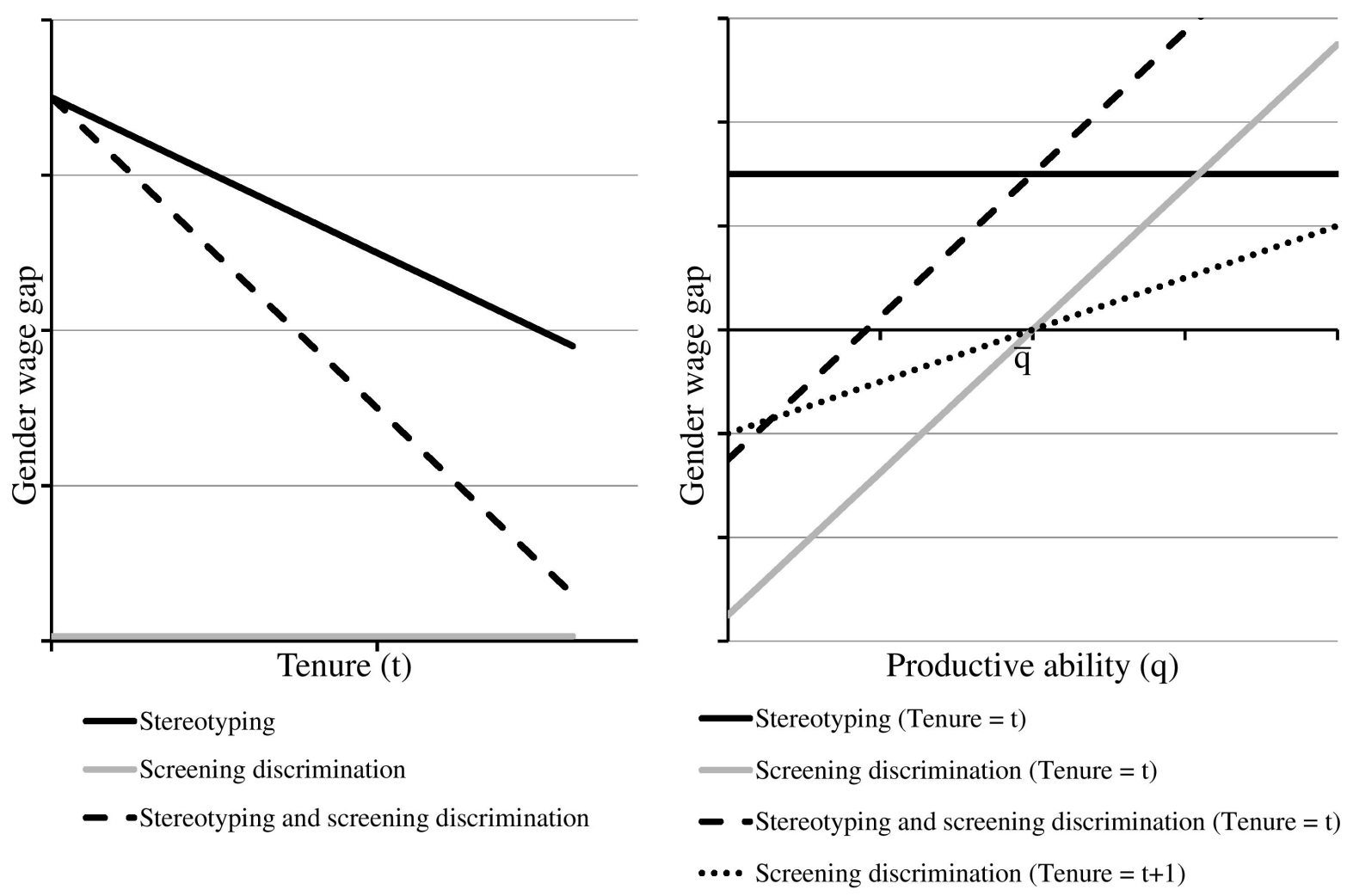

Figure 1: The impact of employer stereotyping and screening discrimination on the gender wage gap by tenure and by productive ability of the worker.

From the graph on the left it can be seen that if employers use stereotyping based on gender then the gender wage gap should be positive and decreasing in tenure. This follows from the biased initial signal weighting less in the assessment of the worker as more signals are received. 
From the graph it can also be seen that screening discrimination in itself does not affect the gender wage gap. In the case where both screening discrimination and stereotyping are present, the gender wage gap decreases more in tenure than in the case without screening discrimination. This illustrates the important aspect of screening discrimination dampening the impact of stereotyping because less weight is put on the initial biased signal.

From the graph on the right in Figure 1 it can be seen that the level of the gender wage gap is independent of the ability of the worker when only stereotyping is present. If screening discrimination is present, the gender wage gap will be increasing in the ability of the worker and no gender wage gap for workers with an average level of ability $(\bar{q})$. When both types of statistical discrimination are present, we get the level shift from the stereotyping and the positive correlation between the ability of the worker and the gender wage gap from the screening discrimination. Finally the graph illustrates the aspect that if screening discrimination is present (with or without stereotyping) then the correlation between the ability of the worker and the gender wage gap will be decreasing in tenure.

From these considerations we arrive at the following simple implications of statistical discrimination which will be taken to the data. If employers screening discriminate based on gender, then the correlation between the wage and the productive ability of the worker will increase in tenure at a higher rate for women than for men. If employers use stereotyping based on gender, then the average wage of women will be lower than the average wage of men, but the wage of women will increase at a higher rate than the wage of men ${ }^{7}$.

\footnotetext{
${ }^{7}$ Notice that one could allow for taste discrimination (Becker (1957)) in this setup. This would imply a gender wage gap. But as taste discrimination is based on employer preferences, it would not change over time. The same intuition can be applied for gender differences in worker preferences.
} 


\section{Data}

The empirical analysis is based on a comprehensive Danish Matched Employer-Employee data set (IDA) merged with birth and family information from The Medical Birth Registry (MFR). In this section I will briefly describe the data sources, the selection criteria imposed to obtain analysis data, and finally, present a number of empirical facts on the main variables of interest.

\subsection{Data sources}

\subsubsection{IDA}

IDA is a matched employer-employee data set constructed and maintained by Statistics Denmark from a wide array of administrative registers ${ }^{8}$. IDA covers all persons, aged 15 to 70 , residing legally in Denmark, and it is available for the period 1980-2012. In IDA measurements are annual. In general, the annual IDA measurements refer to the last week of November in each year. IDA contains a comprehensive set of measurements on the demographic and socioeconomic characteristics of the population. I obtain: age, gender, highest completed education, fraction of year employed, hourly ${ }^{9}$ and yearly wage, accumulated actual labour market experience $^{10}$, and job type in terms of part-time vis-à-vis full-time employment. In addition to these individual specific characteristics, IDA contains a wide range of information about the firms.

\footnotetext{
${ }^{8}$ IDA stands for Integreret Database for Arbejdsmarkedsforskning, which can be translated to: Integrated Database for Labour Market Research.

${ }^{9}$ Hourly wages are only available for individuals employed in the last week of November each year. The hourly wage is calculated by dividing the total gross annual wage payments from the job held at the last week of November by the number of hours worked in the job. The number of hours worked are derived from mandatory pension contributions made by employers.

${ }^{10}$ Statistic Denmark estimates an individual's actual (as opposed to potential) labour market experience using mandatory pension contributions made by employers.
} 
I obtain number of employees, average firm wage, fraction of women in the firm, hiring and firing rates, and whether the firm is in the private sector.

\subsubsection{MFR}

The Medical Birth Registry (MFR) contains information on all births in Denmark by Danish women in the period 1973-2012 including children dead at birth. In addition to the exact date of birth, the register includes person identifiers linking biological parents and the child. The register also has a range of information on the children around the time of birth. I obtain the weight and length at birth. While the register dates back to 1973, not all information can be found all the way back to 1973. In particular the birth weight is only available from 1979.

\subsection{Sample selection}

The sample of individuals used in this paper consists of all individuals entering the Danish labour market between 1980 and 2010. The common definition of labour market entry where an individual is defined to be in the labour market from the year where he/she obtains his/her highest level of education is applied. In addition all individuals born after 1987 are excluded in order to avoid pre-final-education job spells. All non-employment spells and all observations where the wage data quality was to low are excluded. Finally employment spells without workplace identifiers are excluded. This is done to be able to rely on workplace level fixed effects in the estimations in order to take out workplace level variation in the wage setting. In Table 1 the number of excluded observations can be seen.

Column four in Table 1 shows the number of observation in the sample where birth weight is available. Subsample identifiers will be included for whether birth data is available, which is the case for individuals born after 1978. Essentially this subsample will be the relevant sample size 
Table 1: Data Selection

\begin{tabular}{lcccc}
\hline \hline & Total & No workplace & Bad wage quality* & Born after 1978** \\
\hline Observations & $14,216,687$ & $13,409,625$ & $12,351,100$ & $1,134,166$ \\
Spells & $5,289,415$ & $4,901,906$ & $4,329,081$ & 599,859 \\
Individuals & $1,901,689$ & $1,872,712$ & $1,784,814$ & 289,677 \\
\hline \hline
\end{tabular}

Notes: * The quality of the hourly wage measure is assesed by Statistics Denmark. The main issue is the meaure of working hours. ** Birth weight data is only available for individuals born after 1978 .

since the main variables of interest will be identified within this subsample. The full sample mainly helps in the identification of workplace-education level fixed effects. The empirical method is further described in section 4.

\subsection{Descriptive Statistics}

Table 2 below offers descriptive statistics for the sample of individuals born after 1978 split by gender. From the table it can be seen that men have about one year more labour market experience than women, but women have almost a year more schooling than men. In the paper two measures of schooling are used. The first measure is the actual identity of the highest level of education of an individual at a given point in time. The second, which is presented in the table, is the expected duration of the education in years.

The measure of tenure used in this paper is defined as the accumulated labour market experience within a given worker-workplace match. The workplace is observed in November of each year. If a worker is observed in the same workplace for two consecutive November cross-sections, then the accumulated tenure will be defined as the labour market experience accumulated within these two years. From Table 2 it can be seen that men in the sample have about a quarter more tenure than women.

In the sample the women have more children than men, reflecting that women have children 
Table 2: Means and standard deviations of selected variables by gender for the last observation of each individual.

\begin{tabular}{|c|c|c|c|c|c|c|}
\hline & \multicolumn{2}{|c|}{ Total } & \multicolumn{2}{|c|}{ Men } & \multicolumn{2}{|c|}{ Women } \\
\hline & Mean & Std. dev. & Mean & Std. dev. & Mean & Std. dev. \\
\hline Age: $<27$ & 0.40 & 0.49 & 0.41 & 0.49 & 0.38 & 0.49 \\
\hline Age: $27-30$ & 0.43 & 0.50 & 0.42 & 0.49 & 0.44 & 0.50 \\
\hline Age: $30<$ & 0.17 & 0.38 & 0.17 & 0.37 & 0.18 & 0.38 \\
\hline Schooling & 14.47 & 2.23 & 14.13 & 2.24 & 14.84 & 2.16 \\
\hline LM experience & 4.30 & 2.67 & 4.77 & 2.83 & 3.79 & 2.39 \\
\hline Tenure & 2.31 & 1.77 & 2.42 & 1.91 & 2.19 & 1.61 \\
\hline No. of children & 0.56 & 0.81 & 0.45 & 0.74 & 0.69 & 0.86 \\
\hline Child below age 4 & 0.30 & 0.46 & 0.25 & 0.44 & 0.35 & 0.48 \\
\hline Immigrant parents & 0.02 & 0.14 & 0.02 & 0.14 & 0.02 & 0.14 \\
\hline Birth weight & 3.41 & 0.55 & 3.46 & 0.56 & 3.35 & 0.53 \\
\hline Birth lenght & 0.52 & 0.05 & 0.52 & 0.05 & 0.52 & 0.05 \\
\hline Schooling of father & 11.39 & 4.19 & 11.38 & 4.17 & 11.40 & 4.21 \\
\hline LM income of father & 207,175 & 141,560 & 206,781 & 140,637 & 207,605 & 142,562 \\
\hline Hourly wage & 165.08 & 52.65 & 175.49 & 58.95 & 153.70 & 41.91 \\
\hline No. of employees in firm & 411.52 & 1067.60 & 290.02 & 730.58 & 544.30 & 1329.79 \\
\hline Avg. firm wage & 224.99 & 62.75 & 230.87 & 65.75 & 218.56 & 58.64 \\
\hline Public sector employment & 0.36 & 0.48 & 0.21 & 0.41 & 0.53 & 0.50 \\
\hline Part-time employment & 0.16 & 0.36 & 0.15 & 0.36 & 0.16 & 0.37 \\
\hline No. of individuals & 289 & 677 & 152 & 261 & 137 & 416 \\
\hline No. of spells & 599 & 859 & 337 &, 573 & 262 & 286 \\
\hline No. of observations & 1,13 & 4,166 & 640 & 609 & 493 & 557 \\
\hline
\end{tabular}

Notes: Schooling, accumulated labour market experience, and tenure are measured in years. The hourly wage is in 2010 DKK, the birth length is in meters, and the birth weight is in $\mathrm{kg}$.

at an earlier age than men. About $2 \%$ of the sample have immigrant parents, and the average birth weight is $3.41 \mathrm{~kg}, 110$ gram higher for men than women, and the average birth length is 
$52 \mathrm{~cm}$.

The schooling of the father is measured in years in a similar manner to the schooling of the individual described above, and the labour market income of the father at his age of 40 is measured in 2010 DKK. These numbers are similar on average for men and women in the sample. A noticeable gender difference in the Danish labour market is that for this sample 53\% of the employed women work in the public sector while for men this number is $36 \%{ }^{11}$.

The raw gender wage gap can be seen in the table as the difference in hourly wages between men and women. From the table it follows that the gender wage gap in the sample is around $12.5 \%$. Form the table it also follows that $52 \%$ of the individuals are men and that $58 \%$ of the observed employment spells are by men, which reflect that men have more job transitions than women.

\subsection{Measuring Worker Ability}

The empirical method applied in this paper relies on the econometrician having information about the productive ability of the worker which is not or only partially available to the employer at the time of the wage setting. This method dates back to Faber and Gibbons (1996) and Altonji and Peirret (2001) and will be described in more detail in Section 4. In this paper such ability measures are obtained by relying on detailed medical data from the time of birth and intergenerational links.

Using extensive Norwegian data on twins followed from birth to the labour market Black et al. (2007) show that birth weight is correlated with both short and long term outcomes such as

\footnotetext{
${ }^{11}$ In order to accommodate these differences, sector controls are included in the main regressions, and separate regressions are preformed conditional on sector.
} 
child mortality, five-minute APGAR score ${ }^{12}$, IQ, education, and earnings ${ }^{13}$. The results based on birth weight rely on the assumption that employers do not assess birth information in the wage setting process and in any case do not base their decisions on this kind of information.

Figure 2 below shows results from regressing birth weight on years of schooling using the last observation for each individual in the data set and controlling for age and year by including dummies. Estimations are conducted separately for men and women. Birth weight below 2.5 $\mathrm{kg}$ is used as the reference group. Figure 3 shows the results from a similar regression using $\log$ hourly wage as the outcome measure. Both figures are consistent with the results in Black et al. (2005) in showing a clear correlation between birth weight and years of schooling and log hourly wage.

In the case of years of schooling in Figure 2 it can be seen that the results for men and women are remarkably similar showing that individuals with a low birth weight have on average around five months less education than individuals with a high birth weight. From Figure 3 it can be seen that men with low birth weights on average earn an hourly wage around $4.5 \%$ lower than men with high birth weights. For women this difference is at around $2.5 \%$. The gender difference between the two figures can be seen as an indication of a lower return to productive ability of women in the labour market as oppose to the educational system.

A concern with using birth weight as a measure of individual ability could be that the variation could be driven by underweight babies. This does not seem to be the case from these figures. The variations in both years of schooling and log hourly wage are increasing throughout the range of birth weights.

\footnotetext{
${ }^{12}$ The APGAR score is a ten point score based on appearance, pulse, grimace, activity, and respiration five minutes after birth.

${ }^{13}$ Similar results can be found in Conley et al. (2006), Almond et al. (2005), and Behrman and Rosenzweig (2004).
} 


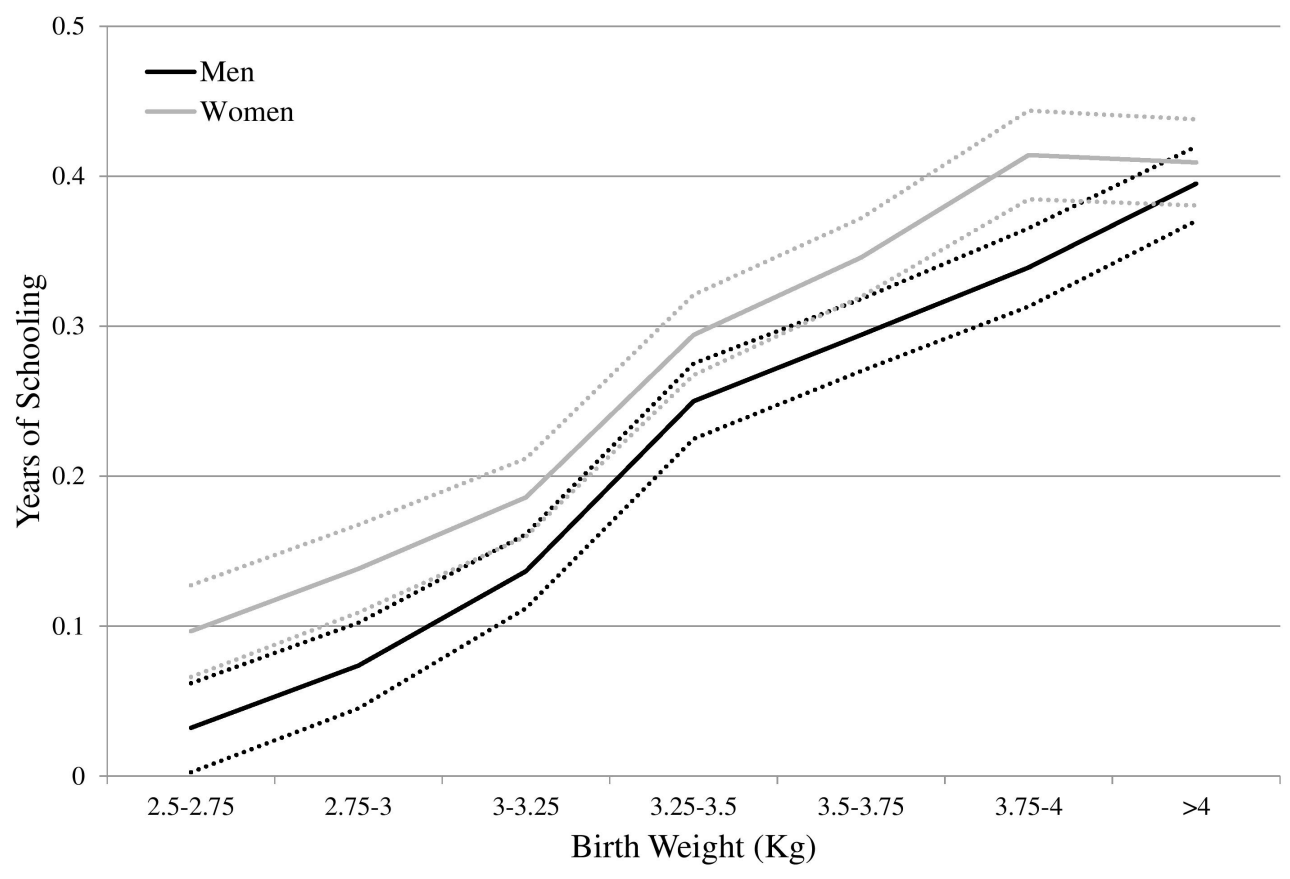

Figure 2: The correlation between birth weight and years of education conditional on age and year. Dotted lines are 95\% confidence intervals.

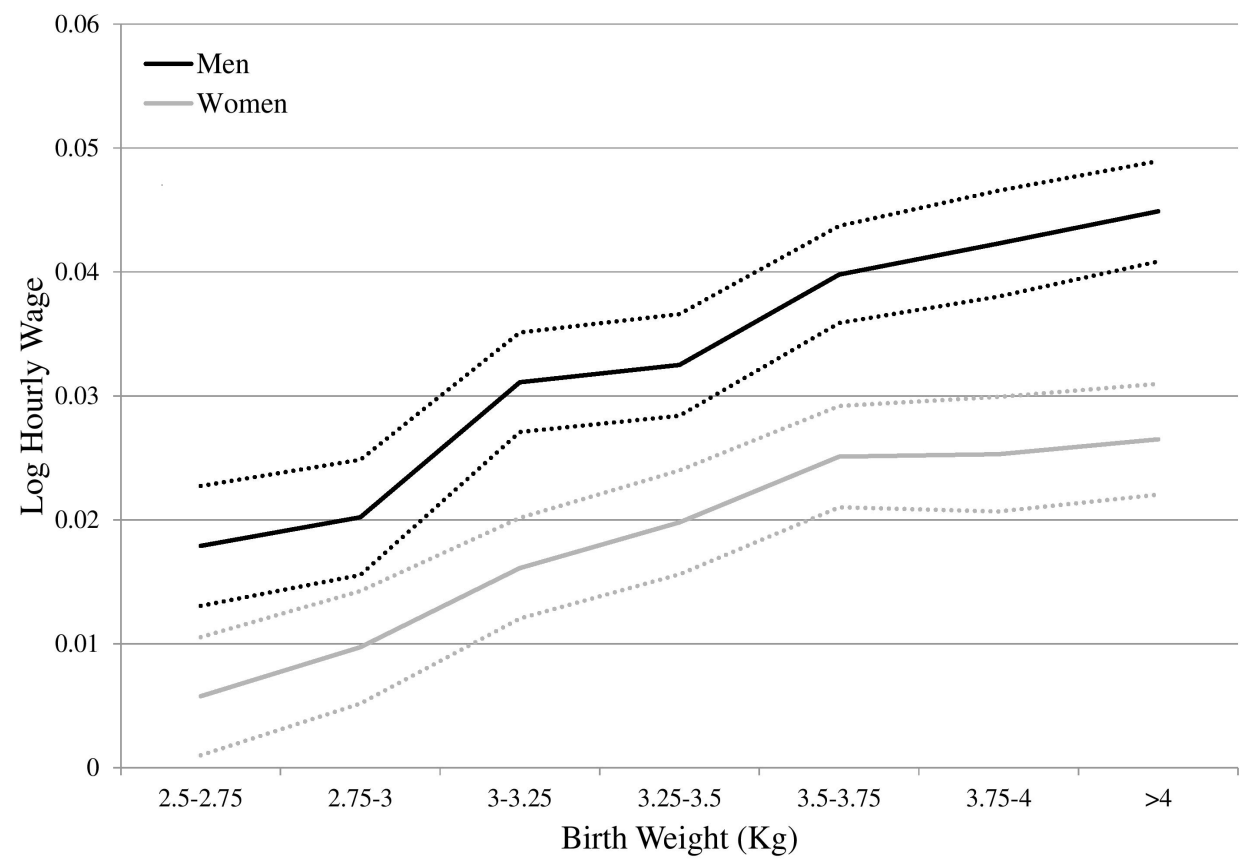

Figure 3: The correlation between birth weight and log hourly wage conditional on age and year. 
Another concern could be that birth weight only affects wages through education. The results in Black et al. (2005) on a range of other outcomes such as IQ test scores, however, point towards birth weight having a wider impact on the ability of the individual. In order to address this concern, birth weight is regressed on log hourly wage controlling for education fixed effects, age and year dummies, accumulated labour market experience cubic, tenure cubic, number of children, child below the age of 4, part-time and public sector indicators, as well as employment entered through a job-to-job transition. From this regression the conditional correlation between birth weight and log hourly wage came out as 0.01 with standard error of 0.001 for men and 0.002 with standard errors of 0.001 for women. Both of these estimates are significant and can be seen as suggestive evidence that birth weight does not only affect the wage through educational achievements.

Differences in birth weight can arise from many channels. The most obvious candidates are genetics, gestational length, and differences in nutritional intake ${ }^{14}$. The results from the literature using twin data indicates that even when closing down the genetic and the gestational length birth weight still is correlated with outcomes such as education, earnings, and IQ. For instance Morgane et at. (1993) show that nutrition in utero can affect the development of the brain. However one might imagine other biological and behavioural explanations ${ }^{15}$. In this paper the exact channels are not central. The main interest as stated in the beginning of this section is that birth weight can be used as a measure of productive ability of the worker which the employers do not assess when setting wages.

The most commonly used measure of worker productive ability in the employer learning literature is test scores from military test. In particular the variable most often used is the AFQT

\footnotetext{
${ }^{14}$ For instance through intrauterine growth retardation (IUGR) affecting fetal growth (Black et al. (2007)).

${ }^{15}$ See also Black et al. (2005) for a discussion on this.
} 
Table 3: Conditional correlation of log hourly wage and the ability measures.

\begin{tabular}{|c|c|c|c|}
\hline & Birth Weight & Education of Father & LM Income of Father \\
\hline \multicolumn{4}{|c|}{ Men: } \\
\hline & $0.0094 * * *$ & -0.0004 & $0.0045^{* * *}$ \\
\hline & $(0.0013)$ & $(0.0003)$ & $(0.0006)$ \\
\hline$N$ & 640,609 & 640,609 & 604,689 \\
\hline \multicolumn{4}{|c|}{ Women: } \\
\hline & $0.0025 * *$ & 0.0001 & $0.0025 * * *$ \\
\hline & $(0.001)$ & $(0.0002)$ & $(0.0006)$ \\
\hline$N$ & 493,557 & 493,557 & 465,371 \\
\hline \multicolumn{4}{|c|}{ Notes: $* p<0.05, * * p<0.01, * * * p<0.001$. Robust standard errors in parentheses. } \\
\hline \multicolumn{4}{|c|}{ The set of controls includes education fixed effects, age and year dummies, accumulated } \\
\hline \multicolumn{4}{|c|}{ labour market experience cubic, tenure cubic, number of children, child below the age } \\
\hline \multicolumn{4}{|c|}{ of 4 , part-time and public sector indicators, as well as employment entered through a } \\
\hline \multicolumn{4}{|c|}{ job-to-job transition. The education of the father is measured in years, and the labour } \\
\hline \multicolumn{4}{|c|}{ market income of the father is measured in 100,000 DKK in 2010 prices. } \\
\hline
\end{tabular}

test score from the American National Longitudinal Survey of Youth $1979^{16}$. Compared to relying on military test scores, the birth weight measure has the clear advantage of being an objective measures in the sense that individuals are unable to affect the outcome of their birth weight. In the case of Denmark medical data also has the advantage of being available for all individuals born in the country by Danish mothers and thereby including women as oppose to the military data. The idea of using birth weight as a measure of the productive ability of a worker opens up the employer learning literature by making it possible to test its implication on a range of new data sets.

While the birth weight measure is considered to be an ability measure which is very likely not to break the assumption of not being completely available to the employer at the time of the

\footnotetext{
${ }^{16}$ See also Kahn (2013) for a discussion on the AFQT score.
} 
wage setting, other more conventional ability measures will also be considered. These rely on the intergenerational correlation of education and income. I will use the years of schooling of the father and the labour market income of the father at his age of 40. These measures might be more likely to break the central assumption of not being available to the employer at the time of the wage setting, but they have the advantage of being commonly used. The intergenerational measures are only included for the subsample where the birth weight measure is available. This is done in order to have a comparable sample. Table 3 shows results of estimating the conditional correlation between the log hourly wage and the two intergenerational ability measures. From this it can be seen that the labour market income of the father at his age of 40 is correlated with the hourly wage of the individual both for men and women even when including the large set of controls. Contrary, once including controls for the education of the individual, the correlation between the education of the father and the hourly wage of the individual becomes insignificant. Since the education of the individual is expected to be available to the employer when setting wages, the education of the father will be considered the least credible of the three measures of the productive ability of the worker not completely available to the employer at the time of the wage setting considered in this $\operatorname{paper}^{17}$.

\section{Empirical method}

The panel nature of the data and the identification of workplaces allow for taking out a large part of the irrelevant variation. In particular, only within workplace variation for workers with the exact same education will be considered. This is done by relying on workplace-education fixed

\footnotetext{
${ }^{17}$ Table 4 in B Appendix shows the pairwise correlations between the three ability measures. From the table it can be seen that all three measures are positively correlated but that the correlation between the intergenerational measures and the birth weight is small.
} 
effects and a large set of controls. Within these workplace-education cells gender differences in the return to tenure will be considered. The modelling setup can be described by the following wage equation.

$$
\log \left(w_{i t}\right)=\alpha_{1} X_{i t}+\alpha_{2} L_{i t}+\beta_{1} G_{i}+\beta_{2} G_{i} * \tau+\beta_{3} A_{i} * G_{i} * \tau+\phi_{F E}+v_{i t},
$$

where $w_{i t}$ is the hourly wage of individual $i$ at time $t, G$ is a gender identifier, $A$ is the measure of productive ability of the worker, $\tau$ is years of tenure in a workplace, $\phi_{F E}$ is a workplaceeducation fixed effect ${ }^{18}$, and $v$ is an iid error term.

The set of controls $(X)$ include the ability measure ${ }^{19}$, age and year dummies, accumulated labour market experience cubic, tenure cubic, number of children, child below the age of 4 , part-time and public sector indicators, employment entered through a job-to-job transition, and number of previous employment spells. In order to account for different trends, the set of controls also include tenure and accumulated labour market experience interacted with the following variables: schooling ${ }^{20}$, part-time, employment entered through a job-to-job transition, public sector, and the ability measure ${ }^{21}$. In addition the regression includes interaction terms between accumulated labour market experience, the ability measure, and the gender identifier.

The second set of controls $(L)$ is included in order to allow for female life cycle trends to differ from male life cycle trends. This is done by including gender interactions with the indicator of having a small child, number of children, age indicators, and year indicators.

Notice that the inclusion of both accumulated labour market experience and tenure in the

\footnotetext{
${ }^{18}$ The model was also estimated without workplace-education fixed effects yielding similar results.

${ }^{19}$ Birth weight, years of education of the father, or labour market income of the father at his age of 40.

${ }^{20}$ The schooling interaction terms are included as years of schooling interacted with tenure and accumulated labour market experience and additionally allowing for separate trends for low medium and highly educated.

${ }^{21} \mathrm{An}$ identifier for whether the birth weight is available in the data for the individual is also included, and workers with birth weight data are allowed to have different trends in all relevant control variables including the interaction term with tenure and accumulated labour market experience.
} 
regression implies that the return to tenure should be thought of as the within workplace return to labour market experience in addition to the market wide return.

$\beta_{1}$ in the log wage equation shows whether a residual gender wage gap is present even after accounting for the large set of controls. If $\beta_{2}$ is positive, then the wages of women increase more in tenure than the wages of men. The model in section 2 shows that an implication of employer stereotyping is that female wages increase more in tenure than male wages.

$\beta_{3}$ in the log wage equation shows whether the conditional correlation between the ability measure and the wage increases more in tenure for women than for men. The model in Section 2 shows that an implication of employers using gender based screening discrimination is that the correlation between the ability measure and wages increased more in tenure for women than for men. This implication of screening discrimination can be verified if the estimate of $\beta_{3}$ is positive.

In order for the estimate of $\beta_{3}$ to capture the above described implication, the central assumption is that the used ability measure contains some information about the productive ability of the worker which is not otherwise available to the employer ${ }^{22}$. Since this assumption is central for the identification, three different ability measures are used, i.e. birth weight, years of education of the father, and labour market income of the father at his age of 40 .

The empirical results in this paper rely on the assumption that the large set of controls and the workplace-education fixed effects are able to take out all irrelevant gender varying information and that the above described additional assumption on the ability measure holds. The results and conclusions presented in the next section are conditional on these assumptions.

In principle the potential bias in the estimates could go both ways. However many of the

${ }^{22}$ This assumption is essentially the insight from the empirical strategy in Faber and Gibbons (1996) and Altonji and Pierret (2001). 
most obvious potential biases will have a tendency to downward bias the estimates. For instance, the measure of tenure, which is central to the empirical strategy, captures only the contracted number of hours. If men have a tendency to work more additional hours and thereby attaining additional experience and reveal their productive ability to the employer, then this would downward bias the potentially positive estimates of $\beta_{2}$ and $\beta_{3}$. Thus, positive estimates should be thought of as lower bounds. However, the paper contributes to the related literature by being able to take out much more of the irrelevant variation in the wages than what has previously been done.

\section{Results}

This section presents the results from testing for statistical discrimination based on gender in the Danish labour market. The two first subsections show the main results from the tests for employer stereotyping and screening discrimination. Subsection three moves outside the modelling setup and shows results on gender differences in the transferability of the employer learning across employers. Finally, subsection four presents robustness checks and show results on the impact of female executives on the level of statistical discrimination.

\subsection{Employer stereotyping}

The model in section 2 implies that if employers use stereotyping based on gender when setting wages and that these initial biased beliefs can be updated then the wages of women will increase more than the wages of men in tenure.

In order to test this implication, the empirical model from the previous section is applied. Workers are compared within cells of individuals with the same exact education and workplace 
taking out variation due to the observable characteristics described in the previous section. The results are consistent with the implications of employer stereotyping if the interaction between the female indicator and tenure is positive, so that female wages increase faster in tenure than male wages.

Table 4 shows the relevant results from the log wage regression described in the previous section. The first column shows that even when looking within individuals working in the same workplace with the same exact education and applying the large set of controls we still see an unexplained residual gender wage gap of $7 \%$.

Column two in Table 4 shows the results from a regression where women are allowed to have different returns to labour market experience and tenure. In the first row in the second column, it can be seen that allowing for these divergent trends have a very small impact on the residual gender wage gap. Thus, the mean difference in the gender wage gap cannot fully be attributed to differences in return to experience and tenure.

The result in the second row of the second column shows the estimate from the interaction between female and tenure. This estimate is positive, implying that women have a higher wage increase in tenure than men. For each year of tenure women increase $0.2 \%$ more in wage than men. The result shown in column two in Table 4 confirms the implication of the model of employers using stereotyping when setting wages.

It might be argued that men and women have different trends in wages due to different impacts of children. This gender difference in relation to children can be split into two parts. The first part is the direct impact by which female labour market participation can be affected by having children more than the male participation both on the intensive and extensive margin. This could in turn have a (potentially) negative impact on the return to tenure.

The second part is the potential indirect impact through the expectation of the employer. If 
Table 4: Gender differences in log hourly wage trends.

\begin{tabular}{lccc}
\hline \hline & $\log ($ hourly wage $)$ & $\log ($ hourly wage $)$ & $\log ($ hourly wage $)$ \\
\hline Women $\left(\hat{\beta_{1}}\right)$ & $-0.0693^{* * *}$ & $-0.0614^{* * *}$ & $-0.1323^{* * *}$ \\
& $(0.0012)$ & $(0.0012)$ & $(0.0012)$ \\
Women $\times$ Tenure $\left(\hat{\beta_{2}}\right)$ & & $0.0022^{* * *}$ & $0.0015^{* * *}$ \\
& & $(0.0001)$ & $(0.0001)$ \\
Controls $(X)$ & Yes & Yes & Yes \\
Life cycle trends $\times$ Women $(L)$ & No & No & Yes \\
Workplace $\times$ Education FE $\left(\phi_{F E}\right)$ & Yes & Yes & Yes \\
\hline$N$ & $12,351,100$ & $12,351,100$ & $12,351,100$ \\
\hline \hline
\end{tabular}

Notes: Robust standard errors in parentheses. * $p<0.1$, ** $p<0.05$, *** $p<0.01$. The controls $X$ include the ability measure, age and year dummies, accumulated labour market experience cubic, tenure cubic, number of children, child below the age of 4, part-time and public sector indicators, employment entered through a job-to-job transition, and number of previous employment spells. In order to account for different trends, the set of controls also includes tenure and accumulated labour market experience interacted with the following variables: schooling, part-time, employment entered through a job-to-job transition, public sector, and the ability measure. An identifier for whether the birth weight is available in the data for the individual is also included, and workers with birth weight data are allowed to have different trends in all relevant control variables, including the interaction term with tenure and accumulated labour market experience. In addition the regressions include interaction terms between accumulated labour market experience, the ability measure, and the gender identifier. Gender specific life cycle trends $(L)$ allow for gender specific impacts of having a small child, number of children, age indicators, and year indicators.

the employer expects female workers to have lower labour market participation in relation to future children, then the employer will take this into account when setting wages.

While the first part should be taken out, the second part is essentially a part of the impact of employer stereotyping based on gender. Column three in Table 4 shows results from a log wage regression where female life cycle trends are permitted to differ from the male life cycle trends. This is done by allowing gender specific impacts of having a small child, number of children, age indicators, and year indicators ${ }^{23}$. From these results it can be seen that the interaction of

\footnotetext{
${ }^{23}$ It might be argued that allowing for gender differences in age trends takes out some of the impact of employer
} 
women and tenure is still positive, implying that the result of gender stereotyping employers does not seem to be driven by the direct impact of gender differences in relation to children.

\subsection{Screening discrimination}

The second type of statistical discrimination assessed in this paper is screening discrimination. Using the model from Section 2, it can be argued that if employers use screening discrimination based on gender and employers are able to update their initial worker assessments in tenure, then female wage changes in tenure should be more strongly correlated with worker ability than male wage changes.

In order to test for this implication the three worker ability measures (birth weight, year of education of father, and labour market income of father at his age of 40) are put to use. Separate $\log$ wage regressions are estimated using each of the ability measures. The log wage regressions include controls as described in the previous section. Thus, workers are compared within cells of individuals at the same workplace and with the same education. The results from the three log wage regressions can be found in Table 5.

Table 3 showed a positive correlation between the measure of productive ability of the worker and the wage for both men and women. The question is now: Is this return to the ability measure changing in tenure and do we observe gender differences? The answer to this question can be found in row two and three in Table 5. Row two shows the change in the return to the ability measure for men, and row three shows the additional change in return to the ability measure for women. From row two it can be seen that the estimate of the change in the return to the ability measure for men is insignificant across all three ability measures. There seems to stereotyping, since stereotyping based on future children might be largest for young women. In this sense the results in column three of Table 5 can be viewed as conservative estimates. 
be no learning about the ability of the male worker within the workplace when taking the accumulation of labour market experience into account. In the literature Schönberg (2007) reports a similar result for male workers based on the American NLSY79 dataset while DeVaro and Waldman (2012), Pinkston (2009), Acemoglu and Pischke (1998), and Zang (2007) conclude the contrary.

Table 5: Ability measure differences in log hourly wage trends by gender.

\begin{tabular}{|c|c|c|c|}
\hline Ability Measure: & Birth Weight & Education of Father & LM Income of Father \\
\hline \multirow[t]{2}{*}{ Women $\times$ Tenure $\left(\hat{\beta_{2}}\right)$} & $0.0015 * * *$ & $0.0015^{* * *}$ & $0.0015^{* * *}$ \\
\hline & $(0.0001)$ & $(0.0001)$ & $(0.0001)$ \\
\hline \multirow[t]{2}{*}{ Ability Measure $\times$ Tenure } & -0.0003 & -0.0000 & -0.0001 \\
\hline & $(0.0004)$ & $(0.0001)$ & $(0.00003)$ \\
\hline \multirow[t]{2}{*}{ Ability Measure $\times$ Tenure $\times$ Women $\left(\hat{\beta_{3}}\right)$} & $0.0008^{* * *}$ & $0.0003 * * *$ & $0.0013^{* * *}$ \\
\hline & $(0.0002)$ & $(0.0003)$ & $(0.0001)$ \\
\hline Controls $(X)$ & Yes & Yes & Yes \\
\hline Life cycle trends $\times$ Women $(L)$ & Yes & Yes & Yes \\
\hline Workplace $\times$ Education $\mathrm{FE}\left(\phi_{F E}\right)$ & Yes & Yes & Yes \\
\hline$N$ & $12,351,100$ & $12,351,100$ & $12,2869,94$ \\
\hline
\end{tabular}

Notes: Robust standard errors in parentheses. $* p<0.1, * * p<0.05, * * * p<0.01$. The controls $X$ and the gender specific life cycle trends $(L)$ are included as described in the note to Table 4 . As in Table 4 the regression also includes a gender identifier and a gender-tenure interaction term.

Row three reveals an increasing conditional correlation between the log wage and the ability measure in tenure for women. This is the case for all three ability measures. This result of the increase in the wage return to the ability measure being larger for women than for men in tenure is in line with the model implication of employers using screening discrimination based on gender when setting wages.

Based on the results in Table 4 and 5 it can be conclude the data is consistent with the 
implications of employers using statistical discrimination based on gender both in terms of screening discrimination and stereotyping.

\subsection{Gender differences in the transferability of employer learning}

The two previous subsections were concerned with the main implications of the model described in Section 2. This section goes beyond the model but uses a similar empirical strategy in order to look into what happens between employment spells. It might be the case that workers are able to carry some of their signals with them into their next employment spell by using previous labour market experience as a signal of their productive ability. If this is the case, then the productive ability of the worker could be revealed not only in tenure but also in accumulated labour market experience.

In the employer learning literature (Schönberg (2007), Pinkston (2009)), it is discussed whether employer learning is transferable across employers. For the purpose of this paper the potential transferability of employer learning is relevant if we can observe differences by gender in trends in the return to learning not only within employers but also between employers. In the empirical strategy described in Section 4 the controls include gender interactions with both accumulated labour market experience and number of previous employments spells. The estimates on these control variables can give some insight on the transferability of employer learning. This paper contributes to the literature on the transferability of employer learning by showing results on gender differences on these matters and by not only looking at the accumulated labour market experience but also the number of previous employments spells.

Table 6 shows results from log wage regressions using the setup described in section 4 on the interaction terms between gender, the ability measures, the accumulated labour market experience, and the number of previous employment spells. Row two in Table 6 shows the results 
Table 6: Ability measure differences in log hourly wage trends across employers by gender.

\begin{tabular}{|c|c|c|c|}
\hline Ability Measure: & Birth Weight & Education of Father & LM Income of Father \\
\hline \multirow[t]{2}{*}{ Women $\times$ Experience } & $-0.0044 * * *$ & $-0.0044 * * *$ & $-0.0044 * * *$ \\
\hline & $(0.0001)$ & $(0.0001)$ & $(0.0001)$ \\
\hline \multirow[t]{2}{*}{ Ability Measure $\times$ Experience } & $0.0026^{* * *}$ & $0.0010 * * *$ & $0.0045^{* * *}$ \\
\hline & $(0.0003)$ & $(0.0001)$ & $(0.0003)$ \\
\hline Ability Measure $\times$ Experience & $-0.0027 * * *$ & $-0.0008 * * *$ & $-0.0038 * * *$ \\
\hline$\times$ Women & $(0.0002)$ & $(0.0001)$ & $(0.0003)$ \\
\hline \multirow[t]{2}{*}{ No. of previous job spells } & $-0.0006^{* * *}$ & $-0.0006 * * *$ & $-0.0006^{* * *}$ \\
\hline & $(0.0002)$ & $(0.0002)$ & $(0.0002)$ \\
\hline No. of previous job spells & $-0.0020 * * *$ & $-0.0021 * * *$ & $-0.0020 * * *$ \\
\hline$\times$ Women & $(0.0002)$ & $(0.0002)$ & $(0.0002)$ \\
\hline No. of previous job spells & $-0.0017 * * *$ & $-0.0006^{* * *}$ & $-0.0024 * * *$ \\
\hline$\times$ Ability Measure & $(0.0002)$ & $(0.0001)$ & $(0.0003)$ \\
\hline No. of previous job spells & 0.0004 & $0.0001 *$ & 0.0003 \\
\hline$\times$ Ability Measure $\times$ Women & $(0.0003)$ & $(0.0001)$ & $(0.0004)$ \\
\hline Controls $(X)$ & Yes & Yes & Yes \\
\hline Life cycle trends $\times$ Women $(L)$ & Yes & Yes & Yes \\
\hline Workplace $\times$ Education FE $\left(\phi_{F E}\right)$ & Yes & Yes & Yes \\
\hline$N$ & $12,351,100$ & $12,351,100$ & $12,2869,94$ \\
\hline
\end{tabular}

\footnotetext{
Notes: Robust standard errors in parentheses. $* p<0.1,{ }^{*} p<0.05$, *** $p<0.01$. The workplace $\times$ education fixed effects, the controls $X$, and the gender specific life cycle trends $L$ are included as described in section 4 and in the note to table 4.
}

from the interaction between the ability measure and accumulated labour market experience. This estimate is positive across all three ability measures. This implies that employer learning is, at least to some extent, transferable across employer in the Danish labour market. This result 
is in line with what is found for male workers in the U.S. in Altonji and Pierret (2001).

The table also shows the interaction between number of previous employment spells and the ability measure. The estimate on this interaction is negative, implying that even though the worker can get a return to his/her productive ability in accumulated labour market experience, some of the learning is lost if the worker has many job transitions. This can be interpreted as a transition cost for the worker from employer learning not being completely transferable across employers.

Turning to the gender differences it can be seen that women's return to accumulated labour market experience and women's return to number of previous employment spells are both lower than men's returns. This implies that the transition costs for women is higher than for men and that the within employment spell results of employer stereotyping and learning presented in Table 4 cannot be generalised to the entire market.

While the initial stereotyping of women to some extent can be offset in tenure, the results in this section point to the updated beliefs not being transferable across employers.

A similar patter can be seen when looking into the gender difference in the return to the measure of productive ability in accumulated labour market experience. The negative estimates on the interaction between ability measure, accumulated labour market experience, and women imply that the initial screening discrimination, which to some extent is offset in tenure, is not transferable across employers.

The results from Table 4 and 5 reveal that the initial screening discrimination and stereotyping in an employment spell could be offset by learning by the employer in tenure. The results in Table 6 point to this not being the case when looking at accumulated labour market experience and number of previous employment spells. It seems that the signal of the productive ability of women suffers from a transition cost across employers. 


\subsection{Robustness}

In order to get an understanding of the generality of the results of screening discrimination and employer stereotyping described in subsections 5.1 and 5.2, the main estimation was conducted on a series of subsamples selected on the basis of the characteristics of the firms and of the workers. This is done in order to get insights on whether it is particular types of firms and workers which experience statistical discrimination.

Workers are distinguished by level of education and by their number of children. On the firm side the sample is split by fraction of women in high-ranking positions, number of employees, average wage within the firm, fraction of new hires drawn from other firms as oppose to unemployment, and by sector of employment, the idea here being that bigger and better firms or firms with many women in top position might be less incline to use statistical discrimination be gender.

Results on the main estimates for each subsample can be seen in Table 7. The main insight from the table is that the results from the previous subsections seem to be stable across the selected subsamples. It is worth emphasizing that the results in Table 7 indicate that bigger and better firms or firms with many women in top position are just as likely to use statistical discrimination by gender as other firms.

From the table it can be seen that the interaction term between gender and tenure is positive across all the subsamples and significant in most cases. This implies that the stereotyping found in the previous section does not seem to be driven be a single subpopulation. The largest estimates are found for the two subsamples where more than $50 \%$ of the executives are females, in the private sector, and in small workplaces. In addition the estimates are increasing in the level of schooling ${ }^{24}$. Here a large estimate should not be taken as a testament of a high level

\footnotetext{
${ }^{24}$ Keeping in mind that such a comparison across regressions should be done with some caution.
} 
of stereotyping for this subsample, but rather that the learning of initial biased beliefs is high in the subsample.

Looking into the gender difference in the estimate on the interaction between the ability measure and tenure, it can be seen that the positive estimate found for the full sample is also present in most of the subsamples. The only exception is when looking into firms with no females in lower executive positions. Here the implication of screening discrimination is not consistent with the data.

The results in this subsection indicate that statistical discrimination, both in the form of stereotyping and in the form of screening discrimination does not seem to be driven by a single subsample of the data and that having a large fraction of high-ranking women in a firm does not seem to have an impact on these matters. 
Table 7: Gender differences in log hourly wage trends by subgroups.

\begin{tabular}{|c|c|c|c|c|c|c|}
\hline & \multicolumn{2}{|c|}{ CEO and top executives } & \multicolumn{2}{|c|}{ Other executives } & \multicolumn{2}{|c|}{ Average workplace wage } \\
\hline & No women & $>50 \%$ women & No women & $>50 \%$ women & 1st Quartile & 4th Quartile \\
\hline \multirow[t]{2}{*}{ Women $\left(\hat{\beta_{1}}\right)$} & $-0.1623^{* * *}$ & $-0.0864 * * *$ & $-0.0318 * * *$ & $-0.1001 * * *$ & $-0.1234 * * *$ & $-0.2335^{* * *}$ \\
\hline & $(0.0072)$ & $(0.0072)$ & $(0.0065)$ & $(0.0061)$ & $(0.0075)$ & $(0.0103)$ \\
\hline \multirow[t]{2}{*}{ Women x Tenure $\left(\hat{\beta_{2}}\right)$} & $0.0006^{* * *}$ & $0.0023 * * *$ & $0.0009 * *$ & $0.0019 * * *$ & 0.0001 & $0.0007 * * *$ \\
\hline & $(0.0002)$ & $(0.0002)$ & $(0.0002)$ & $(0.0001)$ & $(0.0003)$ & $(0.0002)$ \\
\hline \multirow[t]{2}{*}{ Ability x Tenure } & 0.0001 & 0.0002 & 0.0005 & -0.0009 & 0.0002 & -0.0012 \\
\hline & $(0.0005)$ & $(0.0007)$ & $(0.0006)$ & $(0.0006)$ & $(0.0007)$ & $(0.0008)$ \\
\hline \multirow[t]{2}{*}{ Ability x Tenure $\mathrm{x}$ Women $\left(\hat{\beta_{3}}\right)$} & -0.0002 & 0.0002 & $-0.0007 * *$ & $0.0013^{* * *}$ & 0.0001 & $0.0008^{*}$ \\
\hline & $(0.0003)$ & $(0.0004)$ & $(0.0003)$ & $(0.0003)$ & $(0.0003)$ & $(0.0004)$ \\
\hline \multirow[t]{3}{*}{$N$} & $4,823,207$ & $3,751,134$ & $3,603,435$ & $5,794,997$ & $2,899,885$ & $3,419,866$ \\
\hline & \multicolumn{2}{|c|}{ Workplace rank ${ }^{+}$} & \multicolumn{2}{|c|}{ Sector } & \multicolumn{2}{|c|}{ No. of employees } \\
\hline & 1st Quartile & 4th Quartile & Public & Private & 1 to 20 & $500+$ \\
\hline \multirow[t]{2}{*}{ Women $\left(\hat{\beta_{1}}\right)$} & $-0.0863^{* * *}$ & $-0.2074 * * *$ & $-0.0948 * * *$ & $-0.0225 * * *$ & $-0.0313 * * *$ & $-0.1148^{* * *}$ \\
\hline & $(0.0083)$ & $(0.0087)$ & $(0.0064)$ & $(0.0051)$ & $(0.0083)$ & $(0.0104)$ \\
\hline \multirow[t]{2}{*}{ Women $x$ Tenure $\left(\hat{\beta_{2}}\right)$} & $0.0027^{* * *}$ & 0.0001 & $0.0017^{* * *}$ & $0.0008 * * *$ & $0.0017 * * *$ & $0.0017 * * *$ \\
\hline & $(0.0002)$ & $(0.0003)$ & $(0.0001)$ & $(0.0002)$ & $(0.0002)$ & $(0.0003)$ \\
\hline \multirow[t]{2}{*}{ Ability x Tenure } & $0.0013^{*}$ & -0.0013 & -0.0004 & -0.0001 & 0.0002 & -0.0009 \\
\hline & $(0.0008)$ & $(0.0008)$ & $(0.0007)$ & $(0.0004)$ & $(0.0008)$ & $(0.0009)$ \\
\hline \multirow[t]{2}{*}{ Ability x Tenure $\mathrm{x}$ Women $\left(\hat{\beta_{3}}\right)$} & 0.0005 & $0.0012 * * *$ & $0.0012 * * *$ & -0.0003 & 0.0002 & $0.0022 * * *$ \\
\hline & $(0.0004)$ & $(0.0004)$ & $(0.0004)$ & $(0.0002)$ & $(0.0004)$ & $(0.0004)$ \\
\hline \multirow[t]{3}{*}{$N$} & $2,839,888$ & $3,124,941$ & $4,638,864$ & $7,712,236$ & $3,354,185$ & $1,895,267$ \\
\hline & & Education & & Have $\mathrm{Ch}$ & iildren & \\
\hline & Low & Medium & High & No & Yes & \\
\hline \multirow[t]{2}{*}{ Women $\left(\hat{\beta_{1}}\right)$} & $-0.0977 * * *$ & $-0.0230 * * *$ & $-0.0523 * * *$ & $-0.0674 * * *$ & $-0.2029 * * *$ & \\
\hline & $(0.0088)$ & $(0.0051)$ & $(0.0077)$ & $(0.0057)$ & $(0.0077)$ & \\
\hline \multirow[t]{2}{*}{ Women $x$ Tenure $\left(\hat{\beta_{2}}\right)$} & $0.0005^{*}$ & $0.0012 * * *$ & $0.0021^{* * *}$ & $0.0007 * * *$ & $0.0018 * * *$ & \\
\hline & $(0.0003)$ & $(0.0002)$ & $(0.0002)$ & $(0.0002)$ & $(0.0001)$ & \\
\hline \multirow[t]{2}{*}{ Ability x Tenure } & 0.0001 & -0.0002 & $-0.0024 * * *$ & -0.0001 & 0.0003 & \\
\hline & $(0.0007)$ & $(0.0005)$ & $(0.0009)$ & $(0.0005)$ & $(0.0006)$ & \\
\hline \multirow[t]{2}{*}{ Ability $x$ Tenure $x$ Women $\left(\hat{\beta_{3}}\right)$} & $0.0011^{* * *}$ & -0.0000 & $0.0032^{* * *}$ & $0.0009 * * *$ & $0.0006^{* *}$ & \\
\hline & $(0.0003)$ & $(0.0002)$ & $(0.0005)$ & $(0.0002)$ & $(0.0003)$ & \\
\hline$N$ & $2,744,507$ & $5,678,653$ & $3,927,940$ & $3,808,531$ & $8,542,569$ & \\
\hline
\end{tabular}

Notes: Robust standard errors in parentheses. ${ }^{*} p<0.1,{ }^{* *} p<0.05,{ }^{* * *} p<0.01$. The workplace $\times$ education fixed effects, the controls $X$, and the gender specific life cycle trends $L$ are included as described in section 4 and in the note to table $4 .{ }^{+}$The workplace rank is defined by ordering workplaces by the fraction of new hires arriving through job-to-job transitions as oppose to hires arriving from unemployment. 


\section{Concluding remarks}

This paper contributes by setting up a model which integrates two of the most commonly cited strands of the literature on statistical discrimination into one model and by testing the implications of both types of discrimination based on gender using rich Danish full population data.

The paper focuses on two specific types of statistical discrimination based on gender labelled screening discrimination and stereotyping. Stereotyping is based on gender biased beliefs at the mean, and screening discrimination is based on gender differences in the noise of the signal. Both of which are induced by the reaction of employers to incomplete information. The paper uses a signalling model in order to set up a framework which can incorporate both screening discrimination and stereotyping. The integration of both types of statistical discrimination in one model with testable implications is new to the literature.

Using the model, I arrive at two simple implications of statistical discrimination based on gender which are tested on Danish full population data. The first implication says that if employers screening discriminate based on the gender then the correlation between the wage and the productive ability of the worker will increase in tenure at a higher rate for women than for men. The second implication says that if employers use stereotyping based on gender then the average wage of women will be lower than the average wage of men, but the wage of women will increase at a higher rate than the wage of men. It is worth noticing that these implications runs counter to the implications from classic preference based discrimination.

In order to test for screening discrimination, it is necessary to have a measure of the productive ability of the worker which is not completely observable to the employer. This paper shows that the birth weight of an individual is a very useful measure of the productive ability of a worker and is recommendable for other studies seeking such a measure.

I contribute by showing that the data is consistent with the implications of both screening 
discrimination and stereotyping based on gender. When splitting the data into subsamples, it can be seen that these results are remarkably stable across subgroups. I find no evidence of firms with a large proportion of women in high-ranking positions being less likely to statistical discriminate based on gender than other firms.

One of the major advantages in this study is the use of Danish full population register data. This allows for a large set of controls so that otherwise similar men and women can be compared within the same workplace and with the same exact education. This large set of controls is indeed central since the empirical fixed effects methodology used in this line of literature relies on taking out all irrelevant observable gender differences.

It can be argued that the long history of high female participation rates in the Scandinavian labour markets should induce a lower level of statistical discriminative behaviour. Allowing for this logic one can speculate that the findings in this paper on statistical discrimination based on gender in the Danish labour market can be thought of as a lower bound on the statistical discrimination in other countries with less gender integrated labour markets.

Taking the results in this paper at face value they could be used as an argument for some type of affirmative action policies based on gender. The finding of firms with a large proportion of women in high-ranking positions not preforming better on these matters should however give cause for some hesitation. It should also be stressed that the empirical evidence presented in this paper adds to a still small established literature on statistical discrimination based on gender. More studies are needed on the topic, potentially using other empirical strategies, before statistical discrimination based on gender can be viewed as an established fact. 


\section{References}

ACEMOGLu, D., AND J.-S. PISChKe (1998): “Why do firms train? Theory and evidence.," Quarterly Journal of Economics, 113(1).

Almond, D., K. Y. Chay, And D. S. LeE (2005): “The Costs of Low Birth Weight," The Quarterly Journal of Economics, 120(3), 1031-1083.

Altonji, J. G., AND C. R. Pierret (2001): “Employer Learning and Statistical Discrimination,” The Quarterly Journal of Economics, 116(1), 313-350.

ARrow, K., ET AL. (1973): “The theory of discrimination,” Discrimination in labor markets, 3(10), $3-33$.

BECKer GARY, S. (1957): The economics of discrimination. University of Chicago Press, Chicago.

Behrman, J. R., AND M. R. Rosenzweig (2004): "Returns to birthweight," Review of Economics and statistics, 86(2), 586-601.

Black, S., P. DevereuX, And K. G. Salvanes (2007): "From the Cradle to the Labor Market? The Effect of Birth Weight on Adult Outcomes," The Quarterly Journal of Economics, 122(1), 409-439.

CoAte, S., AND G. C. LOURY (1993): “Will affirmative-action policies eliminate negative stereotypes?," The American Economic Review, pp. 1220-1240.

Conley, D., K. W. Strully, And N. G. Bennett (2006): “Twin differences in birth weight: the effects of genotype and prenatal environment on neonatal and post-neonatal mortality," Economics \& Human Biology, 4(2), 151-183.

CORNELl, B., AND I. WelCH (1996): "Culture, information, and screening discrimination,” Journal of Political Economy, pp. 542-571. 
DeVAro, J., AND M. WALdman (2012): “The signaling role of promotions: Further theory and empirical evidence," Journal of Labor Economics, 30(1), 91-147.

FARber, H. S., AND R. GibBons (1996): “Learning and Wage Dynamics,” The Quarterly Journal of Economics, 111(4), 1007-1047.

FRYER, R. G. (2007): "Belief flipping in a dynamic model of statistical discrimination," Journal of Public Economics, 91(5), 1151-1166.

Havet, N., AND C. Sofer (2008): “Why do women's wages increase so slowly throughout their career? A dynamic model of statistical discrimination," Labour, 22(2), 291-314.

KAHN, L. B. (2013): “Asymmetric information between employers," American Economic Journal: Applied Economics, 5(4), 165-205.

LundberG, S. J., AND R. STARTZ (1983): "Private discrimination and social intervention in competitive labor market," The American Economic Review, pp. 340-347.

MANSOUR, H. (2012): “Does Employer Learning Vary by Occupation?,” Journal of Labor Economics, $30(2), 415-444$.

Morgane, P. J., R. Austin-LaFrance, J. Bronzino, J. Tonkiss, S. Diaz-Cintra, L. CinTRA, T. KEMPER, AND J. R. GALleR (1993): "Prenatal malnutrition and development of the brain,” Neuroscience \& Biobehavioral Reviews, 17(1), 91-128.

Moro, A., AND P. Norman (2004): “A general equilibrium model of statistical discrimination,” Journal of Economic Theory, 114(1), 1-30.

Oettinger, G. S. (1996): "Statistical discrimination and the early career evolution of the black-white wage gap," Journal of Labor Economics, pp. 52-78.

PhelPS, E. S. (1972): “The statistical theory of racism and sexism,” The American Economic Review, pp. 659-661. 
Pinkston, J. C. (2003): “Screening discrimination and the determinants of wages," Labour Economics, 10(6), 643-658.

_ (2009): "A model of asymmetric employer learning with testable implications," The Review of Economic Studies, 76(1), 367-394.

SCHÖNBERG, U. (2007): “Testing for asymmetric employer learning," Journal of Labor Economics, 25(4), 651-691.

ZHANG, Y. (2007): "Employer learning under asymmetric information: The role of job mobility," Available at SSRN 1058801. 


\section{A Appendix}

\section{A.1 Appendix}

The updated signal at time $t$ for worker $i$ of gender $j$ is given by:

$$
S_{j}^{i}(t)=q^{i}+\frac{\sigma_{t}^{2}}{t \sigma_{0}^{2}+\sigma_{t}^{2}} \varepsilon_{0 j}^{i}+\frac{\sigma_{0}^{2}}{t \sigma_{0}^{2}+\sigma_{t}^{2}} \sum_{\tau=1}^{t} \varepsilon_{\tau j}^{i} .
$$

The variance of the updated signal is:

$$
\begin{aligned}
\sigma_{S_{j}(t)}^{2} & =\sigma^{2}+\left(\frac{\sigma_{t}^{2}}{t \sigma_{0}^{2}+\sigma_{t}^{2}}\right)^{2} \sigma_{0}^{2}+\left(\frac{\sigma_{0}^{2}}{t \sigma_{0}^{2}+\sigma_{t}^{2}}\right)^{2} t \sigma_{t}^{2} \\
& =\sigma^{2}+\alpha_{1 j}
\end{aligned}
$$

with $\alpha_{1 j}=\frac{\sigma_{t}^{2} \sigma_{0}^{2}}{t \sigma_{0}^{2}+\sigma_{t}^{2}}$.

The mean of the updated signal is:

$$
\begin{aligned}
\bar{\mu}_{S_{j}(t)} & =\bar{\mu}+\frac{\sigma^{2}+\sigma_{\varepsilon_{0 j}}^{2}}{(t+1) \sigma^{2}+t \sigma_{\varepsilon_{0 j}}^{2}+\sigma_{\varepsilon}^{2}} t \bar{\varepsilon}+\frac{\sigma^{2}+\sigma_{\varepsilon}^{2}}{(t+1) \sigma^{2}+t \sigma_{\varepsilon_{0 j}}^{2}+\sigma_{\varepsilon}^{2}} \bar{\varepsilon}_{0 j} \\
& =\bar{\mu}+\alpha_{0 j} \bar{\varepsilon}_{0 j}+\alpha_{t j} t \bar{\varepsilon}
\end{aligned}
$$

where $\alpha_{0 j}=\frac{\sigma_{t}^{2}}{t \sigma_{0 j}^{2}+\sigma_{t}^{2}}$ and $\alpha_{t j}=\frac{\sigma_{0 j}^{2}}{t \sigma_{0 j}^{2}+\sigma_{t}^{2}}$,

and I have that

$$
S_{j}^{i}(t) \sim N\left(\bar{\mu}_{S_{j}(t)}, \sigma_{S_{j}(t)}^{2}\right)
$$

Assuming that the log wage $(w)$ of a worker $i$ from subgroup $j$ at time $t$ is given by the expected productive ability of the worker. The log wage can be written as: 


$$
\begin{aligned}
w_{j t}^{i} & =E\left[q^{i} \mid S_{j}^{i}(t)\right] \\
& =\bar{\mu}_{S_{j}(t)}+\frac{\sigma^{2}}{\sigma^{2}+\sigma_{S_{j}(t)}^{2}}\left(S_{j}^{i}(t)-\bar{\mu}_{S_{j}(t)}\right) \\
& =\frac{\sigma_{S_{j}(t)}^{2}}{\sigma^{2}+\sigma_{S_{j}(t)}^{2}} \bar{\mu}_{S_{j}(t)}+\frac{\sigma^{2}}{\sigma^{2}+\sigma_{S_{j}(t)}^{2}} S_{j}^{i}(t) .
\end{aligned}
$$

The average log wage of workers in group $j$ at time $t$ is given by:

$$
\begin{aligned}
E\left[w_{j t}\right] & =\bar{\mu}_{S_{j}(t)}+\frac{\sigma^{2}}{\sigma^{2}+\sigma_{S_{j}(t)}^{2}}\left(E\left[S_{j}^{i}(t)\right]-\bar{\mu}_{S_{j}(t)}\right) \\
& =\bar{\mu}_{S_{j}(t)} .
\end{aligned}
$$

The change in the variance of the updated signal and the group average log wage over time is:

$$
\begin{aligned}
\frac{\partial \sigma_{S_{j}(t)}^{2}}{\partial t} & =-\frac{\sigma_{\varepsilon}^{2} \sigma_{\varepsilon_{0 j}}^{2}\left(\sigma^{2}+\sigma_{\varepsilon_{0 j}}^{2}\right)}{\left((t+1) \sigma^{2}+t \sigma_{\varepsilon_{0 j}}^{2}+\sigma_{\varepsilon}^{2}\right)^{2}} \\
& =-\frac{\sigma_{\varepsilon}^{2} \sigma_{\varepsilon_{0 j}}^{2} \sigma_{0 j}^{2}}{\left(t \sigma_{0 j}^{2}+\sigma_{t}^{2}\right)^{2}}<0,
\end{aligned}
$$

and

$$
\begin{aligned}
\frac{\partial E\left[w_{t j}\right]}{\partial t} & =\frac{\sigma_{0}^{2} \sigma_{t}^{2}}{\left(t \sigma_{0}^{2}+\sigma_{t}^{2}\right)^{2}}\left(\bar{\varepsilon}-\bar{\varepsilon}_{0 j}\right)>0, \\
\text { when } \bar{\varepsilon}_{0 j} & <\bar{\varepsilon} \leq 0 .
\end{aligned}
$$




\section{A.2 Appendix}

The variance of the updated signal is increasing in the variance of the initial signal:

$$
\begin{aligned}
\frac{\partial \sigma_{S_{j}(t)}^{2}}{\partial \sigma_{\varepsilon_{0 j}}^{2}} & =\frac{\left((t+1) \sigma^{2}+\sigma_{\varepsilon}^{2}\right) \sigma_{\varepsilon}^{2}}{\left((t+1) \sigma^{2}+t \sigma_{\varepsilon_{0 j}}^{2}+\sigma_{\varepsilon}^{2}\right)^{2}} \\
& =\frac{\left(t \sigma^{2}+\sigma_{t}^{2}\right) \sigma_{\varepsilon}^{2}}{\left(t \sigma_{0 j}^{2}+\sigma_{t}^{2}\right)^{2}}>0 .
\end{aligned}
$$

The increase in the variance of the updated signal in the variance of the initial signal will be decreasing over time:

$$
\frac{\partial^{2} \sigma_{S_{j}(t)}^{2}}{\partial \sigma_{\varepsilon_{0 j}}^{2} \partial t}=-\frac{\left((t+2) \sigma_{\varepsilon_{0 j}}^{2}+(t+1) \sigma^{2}+\sigma_{\varepsilon}^{2}\right) \sigma^{2}+2 \sigma_{\varepsilon}^{2} \sigma_{\varepsilon_{0 j}}^{2}}{\left((t+1) \sigma^{2}+t \sigma_{\varepsilon_{0 j}}^{2}+\sigma_{\varepsilon}^{2}\right)^{3}} \sigma_{\varepsilon}^{2}<0 .
$$

The group average log wage is increasing in the initial belief on the average productive ability in the subgroup:

$$
\frac{\partial E\left[w_{t j}\right]}{\partial \bar{\varepsilon}_{j 0}}=\frac{\sigma^{2}+\sigma_{\varepsilon}^{2}}{(t+1) \sigma^{2}+t \sigma_{\varepsilon_{0 j}}^{2}+\sigma_{\varepsilon}^{2}}>0
$$

The difference in the group average wage from the difference in the initial belief of the group average productive ability will be decreasing over time and in the variance of the initial signal:

$$
\frac{\partial^{2} E\left[w_{t j}\right]}{\partial \bar{\varepsilon}_{j 0} \partial t}=-\frac{\sigma_{0}^{2} \sigma_{t}^{2}}{\left(t \sigma_{0}^{2}+\sigma_{t}^{2}\right)^{2}}<0 \text { and } \frac{\partial^{2} E\left[w_{t j}\right]}{\partial \bar{\varepsilon}_{j 0} \partial \sigma_{\varepsilon_{0 j}}^{2}}=-\frac{\sigma_{t}^{2}}{\left(t \sigma_{0}^{2}+\sigma_{t}^{2}\right)^{2}}<0 .
$$

A higher variance of the initial signal dampens the effect of the change in the subgroup average log wage over time due to differences in the initial beliefs.

$$
\frac{\partial^{3} E\left[w_{t j}\right]}{\partial \bar{\varepsilon}_{j 0} \partial t \partial \sigma_{\varepsilon_{0 j}}^{2}}=\frac{2 \sigma_{t}^{2} \sigma_{0}^{2}}{\left(t \sigma_{0}^{2}+\sigma_{t}^{2}\right)^{3}}>0
$$




\section{B Appendix}

Table 8: Pairwise correlations between the ability measures.

\begin{tabular}{lccc}
\hline \hline & Birth Weight & LM Income of Father & Education of Father \\
\hline Birth Weight & 1.0000 & & \\
Education of Father & $0.0371 * * *$ & 1.0000 & \\
LM Income of Father & $0.0196 * * *$ & $0.2319 * * *$ & 1.0000 \\
\hline$N$ & $1,134,166$ & $1,134,166$ & $1,070,060$ \\
\hline \hline
\end{tabular}

Notes: $* p<0.05, * * p<0.01, * * * p<0.001$. 


\section{Economics Working Papers}

2015-20: Karl Fritjof Krassel and Kenneth Lykke Sørensen: Childhood and Adulthood Skill Acquisition - Importance for Labor Market Outcomes

2015-21: Erik Strøjer Madsen and Simon Hartington: Disruptive technologies and networking in telecom industries

2015-22: $\quad$ Anders Rosenstand Laugesen: Asymmetric Monotone Comparative Statics for the Industry Compositions

2015-23: John Kennes, Daniel Monte and Norovsambuu Tumennasan: Dynamic Matching Markets and the Deferred Acceptance Mechanism

2015-24: Anders Rosenstand Laugesen: Extensive Margins of Offshoring and Exporting

2015-25: John Kennes and John Knowles: Liberalization of Birth Control and the Unmarried Share of Births - Evidence from Single Mothers in the Marriage Market

2015-26: Benjamin Friedrich: Trade Shocks, Firm Hierarchies and Wage Inequality

2015-27: Kenneth Lykke Sørensen: Active Labor Market Programs and Reservation Wages: Its a Hazard

2016-01: Alexander K. Koch and Julia Nafziger: Correlates of Narrow Bracketing

2016-02: John Kennes and Daniel le Maire: Competing Auctions of Skills

2016-03: $\quad$ Mette Trier Damgaard and Christina Gravert: The hidden costs of nudging: Experimental evidence from reminders in fundraising

2016-04: Sylvanus Kwaku Afesorgbor and Renuka Mahadevan: The Impact of Economic Sanctions on Income Inequality of Target States

2016-05: Martin Paldam and Erich Gundlach: Jumps into democracy: The transition in the Polity Index

2016-06: Erich Gundlach and Martin Paldam: Socioeconomic transitions as common dynamic processes

2016-07: Rune V. Lesner: Testing for Statistical Discrimination based on Gender 